\title{
Unusual Presentations of Multiple Myeloma: Case Report And Review With Focus On Therapeutic And Psychological Aspects
}

\author{
S Agaja, O Babalola, H Olawumi, A Babatunde
}

\section{Citation}

S Agaja, O Babalola, H Olawumi, A Babatunde. Unusual Presentations of Multiple Myeloma: Case Report And Review With Focus On Therapeutic And Psychological Aspects. The Internet Journal of Orthopedic Surgery. 2006 Volume 6 Number 2.

DOI: $\underline{10.5580 / 529}$

\begin{abstract}
Background: Unusual presentations of multiple myeloma which poses a diagnostic dilemma.

Objective: To report unusual presentations of multiple myeloma and highlight how early detection of these unusual features will encourage early investigation, diagnosis and appropriate management and consequently better prognosis of this difficult disease of multiple myeloma.

Patients and Methods: Two cases of multiple myeloma initially managed at Ela Memorial Medical Centre, Ilorin, were presented. The clinical features, management and outcome were extracted from the case notes. After operations on the patients the histological specimens were sent to University of Ilorin Teaching Hospital (U.I.T.H.). The patients were later transferred to UITH for further management.

Results: The first case report presented with multiple swellings on the right shoulder, left chest wall, and back and weight loss. $X$-ray showed fracture of the left clavicle. The erythrocyte sedimentation rate was normal. Bence-Jones Protein was positive and histological report and Bone Marrow aspiration cytology confirmed multiple myeloma. The second case report presented with inability to use the right upper limb and later developed severe pain on the right shoulder and weakness of the right upper limb. X-ray showed fracture of the upper third of the right humerus. Erythrocyte sedimentation rate was very high and Bence-Jones protein was negative. Histological report was suggestive of multiple myeloma whilst bone marrow aspiration confirmed multiple myeloma. The first case was lost to follow up whilst the second case died during chemotherapy.

Conclusion: Presence of multiple swellings on the body and pathological fractures should suggest that such patients should be investigated for multiple myeloma. Failure to start the investigations will lead to delayed diagnosis, delayed management and very poor prognosis.
\end{abstract}

\section{INTRODUCTION}

Multiple myeloma is a common primary malignancy which affects the bones marrow almost exclusively in adults ${ }_{1,2,3}, 4$.

It is a malignant B-cell lymphoproliferative disorder of the marrow, with plasma cells predominating. The effects on bone are due to marrow cell proliferation and increased osteoclastic activity, resulting in osteoporosis and appearance of discrete lytic lesions throughout the skeleton.

Associated features of the marrow cell disorder are plasma protein abnormalities, i.e paraproteinaemia, increased blood viscosity causing hyperviscosity syndromes and anaemia. Bone resorption leads to hypercalcaemia in about one-third of cases. Late secondary features are due to renal dysfunction and spinal cord or root compression caused by vertebral collapse.

The patient, typically aged 40-65 years, presents with weakness due to anaemia, backache, bone pain or a pathological fracture.

We report these two cases of multiple myeloma presenting with osteocutaneous manifestations as unusual presentations, which resulted in diagnostic dilemma and the consequent delay in treatment.

\section{CASE REPORT 1}

$\mathrm{TF}$, a 50 year old furniture contractor presented with 10 month history of swelling on the left shoulder, 8 month 
history of swelling on the right shoulder, 8 month history of swelling on the left chest wall and in the back and 3 months history of loss of weight.

The swelling on the left shoulder was associated with pain. There was a prior history of carrying wood on the left shoulder and X-ray confirmed a fracture of the left clavicle. He then went to traditional bone setter for treatment. Eight months later, he noticed other swellings on the right shoulder and the lower part of the left side of the chest. There were also swellings in the back. There was no previous history of trauma. There were no swellings in other parts of the body. He complained of loss of weight which started 3 months prior to presentation in the hospital.

There was no history of dizziness or easy fatigability. He had been to some private hospitals before reporting at Ela Memorial Medical Centre, Ilorin. The past medical history was essentially normal.

On examination, he was not pale, not jaundiced, no significant peripheral lymphadenopathy and no pedal oedema. There were swellings on both left and right shoulder joints. There was a prominent mass on the anterior left chest wall between the $4^{\text {th }}$ and $6^{\text {th }}$ intercostal space, midclavicular line measuring $10 \mathrm{~cm}$ by $7 \mathrm{~cm}$. There were also other swellings of various sizes in the back. These swellings or masses were subcutaneous and were not fixed to the underlying bones (Figs 1, 2, 3 \& 4). Vital signs were essentially normal. An impression of metastatic tumour was made and he was booked for biopsy of the left shoulder mass. Packed cell volume was 38\%, white blood cells $6.1 \times 10^{9} / 1$ with differentials of Neutrophils $59 \%$, Lymphocytes $38 \%$ and Eosinophils of 3\%. Erythocyte Sedimentation Rate was $15 \mathrm{~mm} / \mathrm{hr}$. urinalysis for BenceJones Proteins was positive. He had excisional biopsy of the mass on the left shoulder which bled profusely during surgery. The histology report was highly suggestive of multiple myeloma. He was therefore referred to Haematology Department at University of Ilorin Teaching Hospital, for further investigations and chemotherapy. A diagnosis of multiple myeloma was established based on findings of bone marrow plasmacytosis in excess of $30 \%$, serum protein electrophoresis which showed a monoclonal spike in the gamma band, presence of Bence Jones proteins in urine and multiple osteolytic lesions on radiographs of the left shoulder which also showed complete loss of the distal third of the clavicle. He made significant improvement whilst on chemotherapy but was lost to follow-up.

\section{Figure 1}

Figure 1: Operated tumour on the left shoulder and the tumour on the right shoulder.

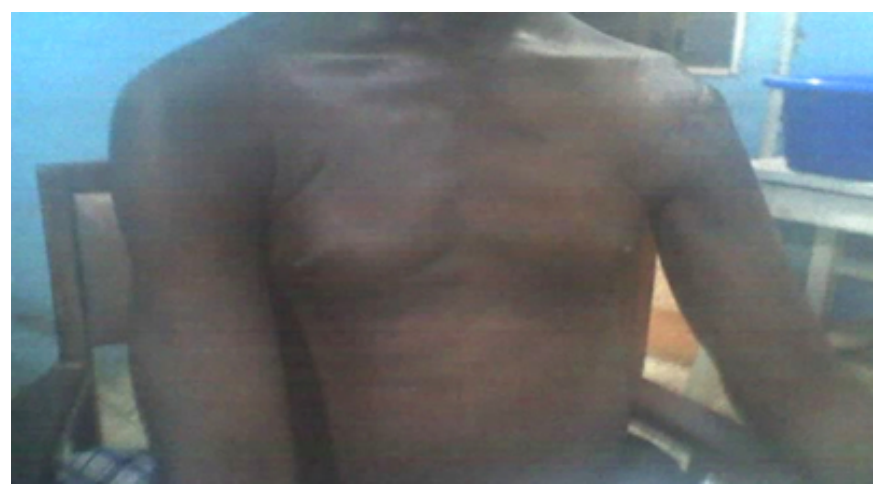

\section{Figure 2}

Figure 2: Operated left shoulder after removal of tumour and tumour on the back.

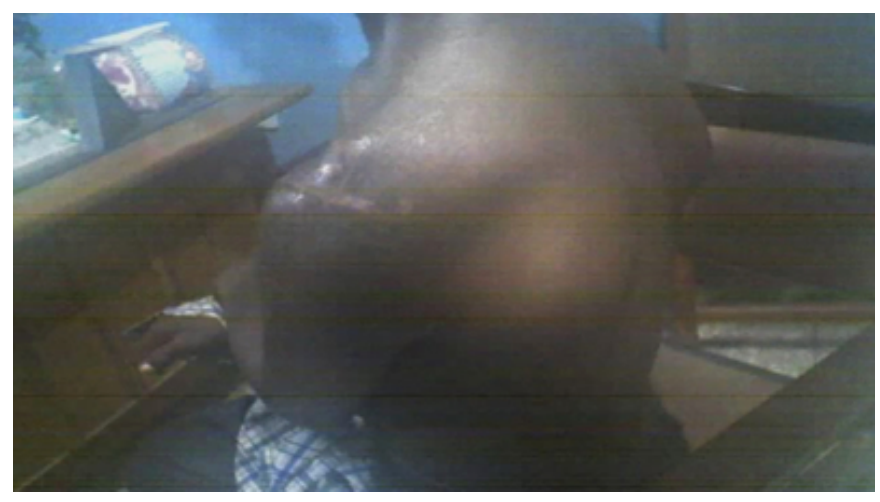

\section{CASE REPORT 2}

MI, a 53 years old carpenter (furniture maker) who presented with inability to use the right upper limb. He claimed that 18 years ago, he had road traffic crash during which he sustained injury to the right shoulder. He claimed he was treated with some injections then and he was alright.

However, in March 2006, he developed severe pain on the right shoulder whilst cutting a tree and this was associated with weakness of the right upper limb which he could no longer use. He was taken to a General Hospital in his village where X-ray of the shoulder was done for which he was told that there was something wrong with the right shoulder. Plaster of Paris (P.O.P) was then applied for $2 \frac{1}{2} 2$ months. After removal of the P.O.P, there was still no improvement as he was still not able to use the right upper limb. He therefore consulted the traditional bone setters but there was still no improvement.

He went back to the General Hospital in his village where 
another x-ray was taken and he was told that something has eaten up the bone at the upper end of the humerus hence his inability to lift the upper limb.

He was then referred to Ela Memorial Medical Centre, Ilorin. The X-rays were reviewed and they revealed presence of pathological fracture of the upper third of the right humerus with the area of fracture severely osteoporotic. He was planned for open reduction and internal fixation with bone graft.

The PCV was $35 \%$, WBC was $7.3 \times 10^{9} / 1$ with Neurophils of $58 \%$, Lymphocytes $37 \%$ and Eosinophil 5\%. The ESR was $45 \mathrm{~mm} / \mathrm{hr}$. Bence- Jones protein in urine was negative.

At Surgery, there was tumour of the upper part of the right humerus with no bones present. The tumour was removed as much as possible and Rush nail was inserted from the acromium through the head of humerus into the distal right humerus. However, haemostasis was well controlled, a tube drain was left in situ and backslab was applied. The wound healed well. Whilst awaiting histology report, he went to the toilet and suddenly discovered he could not walk with the right lower limb.

X-ray of the right femur confirmed communited fractures and he was placed on skin traction. The result of the histology was suggestive of multiple myeloma. He was referred to the Haematology Dept at UITH, Ilorin for further investigations and management. Bone marrow aspiration was done which showed florid plasma cells. Serum protein electrophoresis was also suggestive of multiple myeloma. He was then commenced on chemotherapy.

Few weeks after starting chemotherapy, he developed acute renal failure and also developed pathological fracture of the left humerus. His condition worsened and all efforts to resuscitate him failed and he died.

\section{Figure 3}

Figure 3: Right upper humerus with multiple myeloma

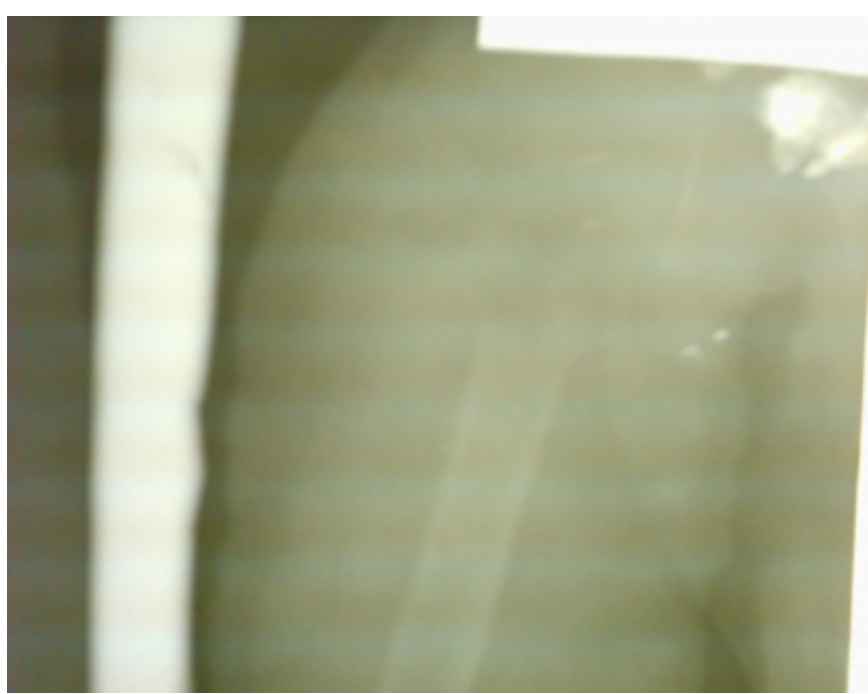

\section{Figure 4}

Figure 4: Right upper humerus after excisional biopsy of the multiple myeloma and insertion of rush nail.

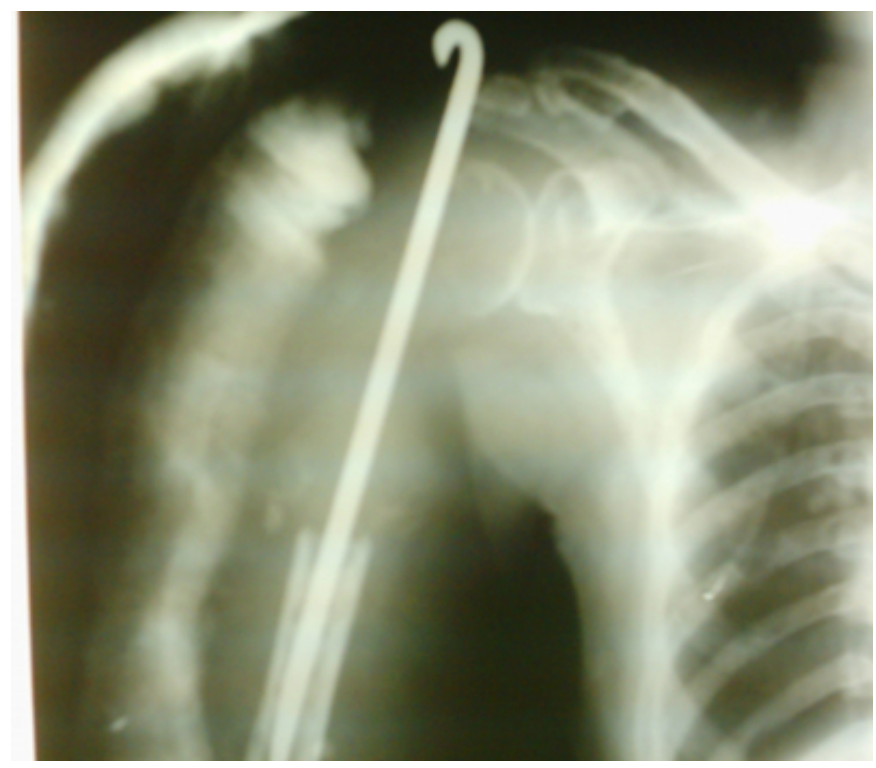

\section{DISCUSSIONS}

Myelomatosis, otherwise called multiple myeloma or plasmacytoma is a malignant neoplasm of plasma cells and is usually associated with abnormalities of protein synthesis ${ }_{5}$. Older age groups are usually affected and the disease is rarely found before the fifth decade of life. Men are affected more often than women. Both patients in our case reports were males and above the age of fifty years. Both were carpenters.

The first case report had swellings in both shoulder joints, 
the anterior left chest wall and the back. These were the cutaneous manifestations of multiple myeloma. In this particular patient, the clavicles on both the right and left were affected, these were the osseous manifestations of multiple myeloma. The second case report gave a previous history of road traffic injury whence he sustained injury to the right shoulder eighteen years previously. The patient was treated for fracture of the upper humerus for several months by various health workers including traditional bone setters. It was because there was no improvement that he was referred to an Orthopaedic Surgeon. The x-ray and operation findings revealed that the proximal part of the right humerus had been destroyed by the multiple myeloma.This is an osseous manifestation of multiple myeloma.

The usual common sites of multiple myeloma are the ribs, vertebrae, skull and pelvis $_{5}$. Our case reports showed that the clavicles, the humerus and the femur were affected.

Both cases were diagnostic delimma because they presented as fracture, non-union and as multiple subcutaneous masses. It was the histological specimens taken during surgery that gave the clues to the diagnosis.

Multiple myeloma may be diagnosed with considerable confidence by laboratory tests. An almost constant feature is high ESR. The ESR in the first case report was $15 \mathrm{~mm} / \mathrm{hr}$ whilst in the second case report it was $45 \mathrm{~mm} / \mathrm{hr}$. Over half the patients have Bence - Jones protein in their urine. In our case reports, only one of them had positive Bence - Jones protein in urine.

After the histological reports for both cases confirmed multiple myeloma, bone marrow aspiration cytology showed plasmocytosis. In fact the second case report showed florid plasma cells in the bone marrow.

In patients presenting with multiple cutaneous masses and pathological fractures, despite mildly elevated ESR and negative Bence-Jones protein, the possibility of multiple myeloma must be given due consideration. Roentgenograms typically show multiple, punched-out, osteo-lytic lesions ${ }_{4}$. In the two case reports, the x-ray findings did not demonstrate the usual radiological findings of multiple myeloma: a permeative, destructive lesion, typically involving the shaft

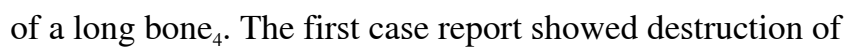
the clavicles whilst the second case report showed the destruction of the upper right humerus. The second case report had pathological fractures of both humerus and the right femur.
Multiple myeloma is a malignant neoplasm of plasma cells which remains incurable with conventional chemotherapy with a median survival between two and three years ${ }_{6}$. The disease is usually chemosensitive and frequently enters a quiescent phase of variable duration (plateau phase) ${ }_{6}$. Despite chemotherapy, ${ }_{6}$ this disease has a universally poor out come, this was the case with our second case.

The tumour had an unusual evolution with the development of extensive extramedullary disease while maintaining mature histological features. It is not uncommon to see the effect of extra osseous extension of intramedullary tumour nodules as a result of erosion of the cortex and subsequent spread beyond the periosteum, although soft tissue involvement itself is unusual except in the rare $\operatorname{IgD}$ multiple myeloma. ${ }_{7}$ This was the experience with our first case report. Foucar described two cases of multiple myeloma that developed prominent extra medullary disease at multiple sites one and four years after initial diagnosis ${ }_{8}$. Our first case report developed extramedullary disease at multiple sites between 8 to 10 months of each other. The second case report gave history of road traffic injury 18 years previously.

Our two case reports were carpenters with specialization in furniture industry. The usual risk factors in multiple myeloma are age (older), race (common in African American), personal history of monoclonal gammopathy of undetermined significance (MGUS) and others are radiation, pesticides, hair dye, certain viruses, obesity and diet. Most people who came down with the disease have no known risk factors $_{3}$. Is there anything in the carpentry occupation of our case reports that could be a risk factor? This needs to be further investigated.

In conclusion, in the tropical environment where investigative facilities are scarce, patients that present to the doctor with multiple swellings and pathological fractures, whatever history the patient gives to the attending physician, multiple myeloma must be ruled out. In addition to a tissue biopsy, bone marrow aspiration, serum protein electrophoresis, ESR and Bence- Jones proteins in urine must be carried out to confirm the diagnosis.

\section{CORRESPONDENCE TO}

Samuel Babatunde Agaja FRCS (Dub), FWACS. Consultant Orthopaedic/Trauma Surgeon, Department of Surgery, University of Ilorin Teaching Hospital, P.O. Box 6462, Ilorin, Nigeria. E-mail: samagnesagaja@yahoo.com Phone no: 08051302598 


\section{References}

1. Russell, R.C.G, William N.S and Bulstrode CJK. Bone Tumours in Bailey and Love's Short Practice of Surgery: 24th Edition Arnold; 2004: 431-440.

2. Duckworth T: Lecture notes on Orthopaedics and Fractures: Blackwell Scientific Publication 1980: 2005-218

3. Solomon L, Warwick D, Nayagam S: Tumours in Apley's System of Orthopaedics 167-200 and Fractures: 8th Edition; Arnold: 2001: 167-200

4. Bland, K.I, Daly J.M and Karakousis C.P: Common Malignant Tumours of Bone In Surgical Oncology:
Contemporary Principles and Practice: McGraw-Hill: 2001: 375-377.

5. Edmonson A.S. Myeloma: In Campbell's Operative Orthopaedics Vol 2: 6th Edition By the C.V Mosby Company: 1980: 1339-1345

6. Pratt G: Molecular aspect of multiple myeloma J. Clin Pathol: Mol Pathol 2002; 55:273-283

7. Jowitt S.N., Jacobs A., Batman P.A., Sapherson D.A, J. Clin Pathol 1994; 47:269-271

8. Foucar K, Raber M, Foucar E, Barlogie B. Sandler CM, Alexanian R: Anaplastic myeloma with massive extramedullary. involvement Cancer 1983: 51: 1: 66-74 


\section{Author Information}

\section{Samuel B. Agaja, FRCS (Dub), FWACS}

Consultant Orthopaedic/Trauma Surgeon, Department of Surgery, University of Ilorin Teaching Hospital

\section{Olasunkanmi M. Babalola, FWACS}

Consultant Orthopaedic/Trauma Surgeon, Department of Surgery, University of Ilorin Teaching Hospital

\section{Hannah O. Olawumi, FWACP}

Consultant Haematologist, Department of Haematology, University of Ilorin Teaching Hospital

\section{Abiola S. Babatunde, FMC Path}

Consultant Haematologist, Department of Haematology, University of Ilorin Teaching Hospital 